\title{
Sentidos de saúde e adoecimento na experiência de familiares de desaparecidos forçados do conflito armado colombiano
}

Rafael Andrés Patiño. Universidade Federal do Sul da Bahia. Gabriela Lamego. Universidade Federal do Sul da Bahia.

\section{Resumo}

O artigo apresenta os resultados de uma pesquisa centrada na experiência traumática de familiares de vítimas de desaparecimento forçado no contexto do conflito armado colombiano, focando nas tentativas de produção de sentido sobre o desaparecimento do ente querido e nas diversas formas em que a experiência violenta se relaciona com a percepção da própria saúde, do corpo e dos processos de saúde/doença. Participaram do estudo 16 mulheres, atendidas por um programa de apoio às vítimas da violência. Foram utilizadas distintas técnicas de produção de informação: entrevistas em profundidade e grupos de discussão. A análise do material discursivo permitiu concluir que para as participantes da pesquisa os mais variados agravamentos de saúde estão relacionados com o desaparecimento do ente querido. Ao mesmo tempo, o adoecimento é atribuído e associado à experiência violenta como uma manifestação da lembrança carregada de angustia do ente querido que sobrevive no psiquismo. Palavras-chave: violência; saúde; trauma psíquico.

\begin{abstract}
Meanings of health and illness in the relatives' experience of forced disappearances in the Colombian armed conflict. This article presents the results of a research centered on the traumatic experience of relatives of victims of forced disappearance in the context of the Colombian armed conflict, focusing on attempts to make sense of the disappearance of the loved ones and the diverse forms in which the violent experience relates with the perception of one's own health, body and health/illness processes. The study was attended by 16 women and different techniques of information production were used: in-depth interviews and discussion groups. The analysis of the discursive material has led to the conclusion that for the participants of the research the most varied health aggravations are related to the disappearance of the loved ones. At the same time, the illness is attributed and associated to the violent experience as well as a manifestation of the anxiety-laden memory of the loved ones in their psyche.
\end{abstract} Keywords: violence; health; psychic trauma.

\section{Resumen}

Sentidos de salud y enfermedad en la experiencia de familiares de desaparecidos forzados del conflicto armado colombiano. Este artículo presenta los resultados de una investigación centrada en la experiencia traumática de familiares de víctimas de desaparición forzada, en el contexto del conflicto armado colombiano. Se enfoca en los intentos de producción de sentido sobre este acontecimiento y en las diversas formas en que la experiencia violenta se relaciona con la percepción de la propia salud, del cuerpo y de los procesos de salud/enfermedad. Participaron del estudio 16 mujeres, atendidas por un programa de apoyo a víctimas de violencia. Fueron utilizadas dos técnicas de producción de información: entrevistas en profundidad y grupos de discusión. El análisis del material discursivo permitió concluir que, para las participantes del estudio, las distintas afecciones de salud están relacionadas con la desaparición de un ser querido. Al mismo tiempo, las enfermedades son atribuidas y asociadas a la experiencia violenta como una manifestación del recuerdo angustioso, del ser querido que sobrevive en el psiquismo. Palabras clave: violencia; salud; trauma psíquico. 
O conflito armado colombiano tem sido cenário das mais diversas formas de violência. Sequestros, assassinatos, tortura, violência sexual, deslocamento e desaparecimento forçado, são algumas das ações sofridas pela população afetada. Nos últimos anos, o governo colombiano iniciou diversas negociações com os grupos armados ilegais orientadas a resolução do conflito, a mais recente delas com a Fuerzas Armadas Revolucionarias de Colombia (FARC). Paralelamente, foram criados programas para o atendimento psicossocial de vítimas da violência, sendo a reparação das pessoas afetadas com o conflito armado, um dos pontos do acordo com o referido grupo guerrilheiro. Este contexto evidencia, ainda mais, a relevância social de estudos, como este, interessados na compreensão de um problema que afeta mais de 8 milhões de vítimas na Colômbia (Unidad para la Atención e la Reparación Integral a las Víctimas, 2017).

Os distintos estudos sobre o tema apontam as consequências devastadoras sobre a saúde de sujeitos e coletividades afetados por dinâmicas de guerra e violência (Faciolince, 2008; Hernández-Holguín \& Alzate-Gutiérrez, 2016). Destacam-se as graves consequências do conflito armado sobre a vida, a morbidade, a mortalidade da população e nos custos dos serviços de saúde na Colômbia (Franco, Suarez, Naranjo, Baez, \& Rozo, 2007). Os mesmos autores indicam que no caso do desaparecimento forçado as consequências sobre a saúde dos familiares é um aspecto adicional do fenômeno, além da vitimização direta do desaparecido e, entre suas conclusões, defendem que a violência é o principal problema de saúde pública da Colômbia.

Diversos autores afirmam, ainda, que a agressões e os modos de menosprezo sofridos em contextos de guerra ou de violência generalizada podem ter efeitos traumáticos: a pessoa afetada, em alguns casos, não consegue produzir um sentido sobre o acontecimento violento, quando o mesmo supera as capacidades de simbolização. Seguindo a teoria do reconhecimento intersubjetivo de Honneth (2003), é possível que as formas de desrespeito e menosprezo próprias de um conflito armado afetem diretamente a autorrelação prática dos sujeitos, produzindo uma ferida moral de ordem não apenas física - no caso de tortura, por exemplo - mas, psíquica:

é visível que tudo o que é designado na língua corrente como "desrespeito" ou "ofensa" pode abranger graus diversos de profundidade na lesão psíquica de um sujeito (...) toda tentativa de se apoderar do corpo de outra pessoa, empreendida contra a sua vontade e com qualquer intenção que seja, provoca um grau de humilhação que interfere destrutivamente na autorrelação prática de um ser humano, com mais profundidade do que outras formas de desrespeito, pois a particularidade dos modos de lesão física, como ocorrem na tortura ou na violação, não é constituída, como se sabe, pela dor puramente corporal, mas por sua ligação com o sentimento de estar sujeito à vontade de um outro, sem proteção, chegando a perda do senso de realidade (Honneth, 2003, pp. 214-215)

Alguns estudos apontam que os acontecimentos traumáticos podem ter como consequência diversos distúrbios, entre eles episódios de ansiedade, transtornos do sono, manifestações psicossomáticas, quadros depressivos etc. (Farias, 2008; Muñiz, Londoño, Correa, Patiño, \& Restrepo, 2005; Rodriguez, De La Torre, \& Miranda, 2002). No plano coletivo, a violência sistemática gera rupturas nos laços sociais, nas redes de apoio comunitárias, familiares e institucionais, aspectos estes que constituem a dimensão social do trauma ${ }^{1}$ (MartínBaró, 1990).

No caso específico dos familiares de vítimas de desaparecimento forçado, a ausência do corpo e a incerteza sobre morte do ente querido produzem duas dificuldades adicionais para a elaboração da perda, já que não é possível realizar os rituais de passagem (ritos fúnebres) necessários no processo de luto (Gennep, 2011). Da mesma forma, os estudos clássicos e contemporâneos sobre o luto apontam que o sofrimento psíquico produzido pela perda de um objeto de amor faz parte de um processo normal que precisa ser experimentado para superar a perda de um ente querido. Neste sentido, tanto Freud (1917/1996), como Butler (2001) mostram como o luto é resolvido, em alguns casos, quando o sujeito incorpora pela via da identificação, características do objeto amado perdido. No caso dos familiares de desaparecidos forçados, este caminho psíquico parece mais complicado porque os dois obstáculos adicionais apontados acima condicionam o percurso normal do luto. Aparecem, então, intensas e persistentes emoções e sentimentos, como medo, ódio, rancor, culpa etc, que caracterizam a ferida moral sofrida pelo sujeito nestas condições. Uma perda pode transformar o sentido de si mesmo: o sujeito nunca será o mesmo depois desta experiência (Duque, Arango, \& Marín, 2010). Neste quadro, os familiares de desaparecidos forçados podem permanecer em um estado de enlutamento por tempo indefinido. No entanto, deve-se 
considerar que, apesar destas dificuldades apontadas, existem distintas alternativas para a elaboração da perda, mesmo na situação descrita (Patino, Chaves, \& Farias, 2015).

Apesar das barreiras que a não realização do funeral impõe para os sobreviventes, estes realizam diversas tentativas para significar o desaparecimento do ente querido e elaborar o luto, entre elas a busca pela verdade e a justiça através dos julgamentos dos responsáveis. Mas, além dessas ações, que às vezes possuem um caráter coletivo, os obstáculos para significar a perda se evidenciam em distúrbios da saúde, somatizações, enfermidades e sintomas que são explicados pelas vítimas em função da experiência violenta.

Neste artigo, apresentamos os resultados de uma pesquisa centrada na experiência traumática de familiares de vítimas de desaparecimento forçado no contexto do conflito armado colombiano, atendidos pela Comisión Nacional de Reparación y Reconciliación (CNRR) e pertencentes à ONG Madres de la Candelaria Caminos de Esperanza na cidade de Medellín, focando nas tentativas de produção de sentido sobre o desaparecimento do ente querido e as diversas formas em que a experiência violenta se relaciona com a percepção da própria saúde, do corpo e dos processos de saúde/ doença.

Para tal fim, partimos do pressuposto epistemológico de que a saúde humana envolve as disposições biológicas (constitucionais e ecológicas), discursivas (subjetivas e sócio-culturais) e as ocasionais (acidentais e circunstanciais) (Echavarría, 2011), o que será equacionado na análise de cada caso, individual ou coletivo. Essa tríade determina a presença, ou não, de trauma psíquico diante de um acontecimento violento e as consequências subjetivas derivadas dele.

\section{Método}

Do ponto de vista epistemológico, a pesquisa se fundamentou na perspectiva histórico-cultural da Psicologia Social, a partir de um desenho qualitativo. A pesquisa qualitativa concebe a relação dialógica entre o pesquisador e o participante, entendendo que o primeiro reconhece que faz parte da realidade que investiga - e, por isso, põe em jogo sua própria subjetividade - e o segundo participa da construção de conhecimento, é ativo, significa, modifica-se e afeta ao sujeito que conhece. Essa concepção da relação participante-pesquisador na pesquisa implica que a subjetividade desempenha um papel fundamental no processo de investigação, porque introduz a significação como parte fundamental da pesquisa (González Rey, 2000).

Optou-se no desenho da pesquisa, por um estudo de casos múltiplos (Stake, 2007). Participaram 16 mulheres: nove mães, quatro irmãs, uma tia e duas esposas dos desaparecidos, atendidas por um programa de apoio às vítimas da violência.

Utilizamos distintas técnicas de produção de informação. Entrevistas em profundidade, as quais entendemos como um sistema conversacional que objetiva a produção de campos de significação da experiência pessoal (González Rey, 2005). Esta técnica "parte do pressuposto de que cada ator social tem seu próprio sentido que se faz explícito no discurso" (Marín, 2004, p. 189). A partir desta técnica foi possível reconstruir a trajetória de vida dos participantes, centrando-se em suas experiências como vítimas. O guia da entrevista foi construído de temas preestabelecidos. Tais temas funcionaram como categorias orientadoras relacionadas às esferas da subjetividade individual ou social dos participantes, em articulação com os objetivos da pesquisa. Desta forma, as significações e dinâmicas psicossociais associadas ao desaparecimento do ente querido foram um dos temas. Dentro desta categoria, a relação com o corpo, a saúde e a doença emergiram como temas centrais a serem analisados.

O guia da entrevista também orientou os grupos de discussão realizados com as participantes. Similares dos grupos focais têm fundamento teórico na linguística e na sociologia. Funcionam como "um marco para captar representações ideológicas, valores e formações imaginárias e afetivas dominantes em grupos, setores ou classes sociais determinadas ou na sociedade em conjunto" (Galeano, 2004, p. 190).

O processo do trabalho de campo foi realizado em dois momentos: no primeiro foi realizado um estudo piloto com participantes atendidos pela Comisión Nacional de Reparación y Reconciliación (CNRR), na cidade de Medellín; em seguida, foram incluídos membros da ONG Madres de la Candelaria Caminos de Esperanza. Ao todo, o trabalho de campo teve uma duração de 4 meses, nos quais foram realizadas as entrevistas em profundidade, os grupos de discussão e foi acompanhada a cotidianidade da referida ONG. No trabalho de campo podemos constatar que oferta de um lugar de escuta destes acontecimentos violentos foi bem acolhida pelos participantes da pesquisa, e algumas das participantes da pesquisa reconheceram 
esse espaço como um lugar possível para ressignificarem suas experiências.

O material discursivo produzido foi analisado com base em categorias orientadoras e uma lógica adutiva (que permitia a emergência de novas categorias), em uma unidade hermenêutica no programa Atlas.ti 6.2 para análise de dados qualitativos. Predominantemente, neste artigo é descrita a categoria Sintomas e Experiência Corporal. Em todas as etapas da pesquisa foram respeitados os critérios éticos como confidencialidade e anonimato. Todos os participantes assinaram um Termo de Consentimento Livre e Esclarecido (TCLE) e seus nomes foram alterados para evitar a identificação. As narrativas originalmente em espanhol foram traduzidas para o português. Cada fala inclui o parentesco da entrevistada com o ente querido desaparecido e o ano do seu desaparecimento.

\section{Resultados e discussão}

O sofrimento produzido pelo desaparecimento forçado de um ente querido está determinado em grande parte pelo desconhecimento dos acontecimentos que envolvem o ente querido, esta incerteza da vida ou da morte do familiar produz um intenso sofrimento psíquico. A impossibilidade de realizar a prova de realidade (Freud, 1917/1996) e os rituais de passagem (velório, funeral e outros) (Gennep, 2011) constituem barreiras adicionais para a elaboração normal do luto. Desta forma, a perda do ente querido torna-se um acontecimento traumático que supera as possibilidades de significação para muitos familiares dos desaparecidos, já que o trauma pode ser definido como o núcleo de uma experiência para a qual não haveria possibilidade de representação ou que ultrapassa as possibilidades de simbolização do sujeito (Farias, 2008). Ao mesmo tempo, o trauma não deve ser reduzido a sua dimensão individual porque ele possui consequências sociais, especialmente, nos casos de comunidades afetadas de forma sistemática por dinâmicas de violência, que produzem rupturas nas relações familiares e comunitárias. Consideramos que esta perspectiva psicossocial do traumático é mais adequada para abordar o fenômeno, porque não o limita a sua dimensão individual (Martín-Baró, 1990).

O desaparecimento de um filho, esposo, marido, irmã, pai, mãe, entre outros, planta uma dúvida poderíamos dizer - obsessiva e não resolvida sobre os fatos, os motivos, os eventos e as ações derivadas do acontecimento. Tal situação implica em uma diferença marcante a respeito da morte:

Quando ele desapareceu, minha filha me disse: mãe, a gente ficou órfã. Mas, pelo menos você fez o funeral do meu pai, e o que sabemos de Cesar? Quer dizer, ela me fez compreender, e veja que é verdade, não sabemos nem por que o sequestraram. (Marta, filho, 2001)

Ao mesmo tempo, o desaparecimento é valorado como pior do que a morte devido ao desconhecimento dos fatos associados. Desta forma, os motivos relacionados ao desaparecimento fazem parte dos sentidos que, por sua vez, integram o sistema que constitui a própria subjetividade (González Rey, 2005). Não poder conhecer o motivo do desaparecimento do ente querido é uma das razões pelas quais o evento torna-se traumático, não simbolizável. A incerteza mantém uma espera constante, porque o ente querido permanece vivo:

A gente espera ele todo dia, quando toca o telefone de noite penso que é ele, chega um táxi e penso que ele veio, vou no centro e presto atenção para ver se alguém se parece com ele, então é uma incerteza terrível. Enquanto a gente enterra um ente querido ..... veja, por exemplo, há um mês enterramos a esposa do meu cunhado, mas a gente sabe [do] que morreu e sabe onde está. (Flora, filho, 2000)

A comparação com a morte de pessoas próximas repete-se com frequência nos depoimentos, porque o desaparecido sobrevive no imaginário de seus familiares, assim, a dúvida não resolvida se interpõe no caminho do luto. De um lado estaria a tristeza e a aceitação da morte; e do outro, a angústia associada à incerteza do desaparecimento. Nessa direção se expressa Anati (G2, filho, 2006):

Eu sempre achei horrível, porque a pessoas me dizem, mas seus [outros] filhos foram mortos. No entanto, [para eles] eu realizei um funeral cristão e sei onde estão. Mas, não sei se mataram meu filho, não sei onde o jogaram, alguns falam que o jogaram no rio, outros que numa cova, isso é horrível, eu me pergunto todos os dias se será verdade que está morto. Eu ainda tenho uma esperança, uma ilusão (...) Então isso é uma angústia que a gente mantém diariamente, às vezes a gente acorda chorando (...). Deus saberá até onde nos leva com essa incerteza.

Essa situação estabelece um paradoxo que contrapõe a esperança da sobrevivência do ente 
querido com a angústia originada na incerteza sobre o destino do mesmo. Ao mesmo tempo, a ausência do corpo impossibilita a realização do ritual de despedida, peça fundamental de elaboração do luto. A dúvida não apenas faz com que o ente querido permaneça vivo no psiquismo - "não sei se está com fome ou com frio, se está morto ou vivo" (Maria, filho, 2002) - como também vem acompanhada de uma recordação que atormenta:

É tão doloroso, tão doloroso que é algo que não desejo nem para o meu pior inimigo. A vida toda, todos os dias da vida, a gente acorda de amanhã e lembra-se desse filho, nos espaços do dia, nunca se apaga da mente. Esse filho estará doente ou não? É doloroso, muito doloroso. (Maria Diosa, filho, 2003)

Tradicionalmente, a visão patológica da memória associa-se ao esquecimento, à impossibilidade de recordação de fatos ou situações, seja em decorrência de lesões que afetam de distintas formas os processos mnêmicos ou como resultado da repressão ou recalque de representações impedidas de se tornarem conscientes. O que os relatos dos familiares de desaparecidos mostram é o fenômeno contrário: a incerteza produz uma falha na memória, mas neste caso não se trata de esquecimento e sim de uma lembrança ultrapresente ${ }^{1 .}$

A lembrança ultrapresente na vida dos familiares de desaparecidos forçados pode ser entendida como "excesso de memória", no sentido explicado por Ricoeur (2010). O excesso de memória é uma forma de "memória-repetição", assim como o outro lado da mesma moeda é a "insuficiência" de memória, quando lembranças são barradas (recalcadas) e substituídas por sintomas. "O que uns cultivam com deleite lúgubre, outros evitam com consciência pesada, é a mesma memória repetição" (p. 93). Deleite lúgubre, como o que os familiares de desaparecidos acumulam na lembrança atormentadora do possível sofrimento que o ente querido ausente deverá estar sentindo e na recordação coletiva e constante do seu desaparecimento, quando realizada de forma acrítica e sem o objetivo de construir uma lembrança sossegada e tranquila do desaparecido. A incerteza, então, mantém o ente querido vivo e, portanto, sofrendo no imaginário do sujeito que se lamenta. Além disso, a incerteza alimenta a esperança do retorno do ausente, tornando impossível o trabalho do luto.

Neste processo, os sujeitos realizam tentativas para significar a experiência violenta e os acontecimentos a ela relacionados. Uma dessas tentativas se dá em torno da significação do próprio corpo e das mudanças relacionadas com a saúde. O sofrimento derivado da incerteza e da impossibilidade de significar a perda se inscreve no próprio corpo quando o acontecimento violento se torna causa e explicação de dores e processos de adoecimento.

Nessa dinâmica, dores de cabeça, pressão alta, insônia, depressão, doenças como o câncer e outras mudanças corporais passam a ser explicadas em função da experiência violenta. Há, no entanto neste processo, uma tentativa malsucedida de superar a experiência traumática enquanto procura de sentido dos acontecimentos não simbolizados. O que não se simboliza reaparece como sintoma e, ao mesmo tempo, a tragédia vivida torna-se o motivo para adoecer, no relato das participantes. O corpo dói e adoece:

Eu tive uma dor terrível, uma dor de cabeça, e eu chorei, chorei, chorei..., então o médico me disse que era estresse, e me receitou comprimidos para relaxar. Mas, esses comprimidos me faziam dormir e me deixavam boba, então como eu não podia estar assim, decidi que tinha que me controlar, eu mesma. Mas, as versões livres dos paramilitares me lembram de tudo isso, e eu fico doente e aumenta a minha pressão. (Maria, filho, 2002)

Segundo Honneth, (2003) "é típico dos três grupos de experiências de desrespeito, que se distinguem analiticamente dessa maneira, o fato de suas consequências individuais serem sempre descritas com metáforas que remetem a estados de abatimento do corpo humano" (p. 218). O autor se refere a experiências de desrespeito, entre as quais se encontram o maltrato físico, a privação de direito e a exclusão e as degradações e ofensas. Neste caso, o desaparecimento do ente querido está associado frequentemente a uma sensação de desproteção, perda de direitos e da dignidade e, ao mesmo tempo, de extrema vulnerabilidade corporal diante do outro perpetrador da violência.

No relato acima, a série de sintomas é desencadeada a partir do encontro de Maria com os algozes que relatam os crimes cometidos, no processo de Justicia y Paz. No caso de Piedade (marido e filho, 1996) é no aniversário de desaparecimento de seu filho e seu marido, a época em que as dores no corpo se intensificam: "eu mantenho uma dor de cabeça todos os dias, constante, sempre estou estressada, chega dezembro e para mim é um tormento, sempre suando".

Ao mesmo tempo em que a experiência traumática se sente como dor no próprio corpo também são 
relatados outros tipos de sintomas, um deles é a insônia: "Tento esquecer, mas não posso. Estou pensando em meu filho o tempo todo, eu não durmo à noite, estou sempre pensando que vai ligar para mim e voltar logo" (Flor E3, Mãe, 2000).

$\mathrm{Na}$ experiência dos familiares de desaparecidos, as emoções e o sofrimento derivados do acontecimento violento são a gênese de distintos processos de adoecimento. Neste caso, é o ódio que explica a doença:

Eu fico doente pelo ódio, a cólera, o ressentimento e o medo, eu tomo medicamentos, muitas vezes, sem necessidades, porque eu sei que se odeio uma pessoa, se sinto raiva, cólera e estou com medo isso causa em mim gastrite. O medo me faz sentir o calor aqui [na barriga] e gastrite. E o ódio me faz sentir dor cabeça. (Marta, Esposo, 2001)

Cada um dos sintomas é explicado e relacionado com um sentimento particular, seja o medo ou o ódio. O sofrimento, portanto, não é apenas psíquico, ele está acompanhado da experiência do corpo que adoenta e as doenças serão explicadas a partir daí pelo desaparecimento do ente querido. Amigdalite, pressão alta, tumores, insônia e AVC são algumas das doenças que os familiares de desaparecidos relacionam com o desaparecimento. Não poder esquecer, não parar de pensar no destino dele é o que explica esses e outros sinais no corpo:

Eu pediria que me dessem uma indenização para eu sustentar o filho que ficou e as netas, esse é meu desejo, saber que pude sepultá-los ou que não foi possível encontrá-los. Eu acho que com isso passaria minha doença (...) A doença é o estresse, a pensadera ${ }^{2}$. Eu penso todos os dias dia e noite, onde estiver. (Piedade, esposo, filho, 1996)

A perda dos entes queridos não deixa apenas um vazio afetivo, mas em algumas ocasiões, dependendo do lugar que ocupava o desaparecido, também uma insegurança econômica. O pensamento vira uma tortura constante que não dá trégua. Os problemas, as doenças, as dificuldades e as calamidades posteriores são explicados pelo desaparecimento do ente querido. Em outras palavras, o desaparecimento se torna o motivo de todas as fatalidades posteriores, como descreve Piedade (esposo, filho, 1996) sobre o ocorrido com seu filho depois do assassinato e desaparecimento de seu esposo e de seu outro filho:

Ele se jogou na rua para se drogar devido ao que nos aconteceu na nossa terra. Ele me falava que se sentia triste, desiludido porque não estava o pai, nem o irmão. Então quando mataram o outro [irmão] ele se jogou na rua, já não se interessava por nada e se drogou, pegou uma tuberculose, um tumor na cabeça, um câncer, e isso o matou há seis meses.

Doenças, adicções, depressão e qualquer infortúnio torna-se uma consequência do desaparecimento do ente querido. $\mathrm{O}$ acontecimento é julgado como sendo o elo determinante dos infortúnios que decorrem da perda vivida. Um exemplo disso é a perda de interesse pelo mundo, característica de quadros depressivos:

Eu me rendi à tristeza e à dor. Dediquei-me a comer e dormir um ano inteiro. Como me mandavam o salário da empresa dele, eu apenas pagava as contas e comia; dormia e comia... Às vezes meus filhos chegavam da escola e nem comida tinha para eles, ou seja, me rendi à depressão. Foi horrível, não procurei ajuda, não fiz nada. (Marta, Esposo, 2001)

Entendemos que não existe uma relação automática entre o desaparecimento de um ente querido e a somatização ou surgimento de mudanças no corpo, mas o sentido negativo de tal acontecimento se relaciona com a experiência de saúde ou de doença. Ao mesmo tempo, a prova de realidade não leva à elaboração da perda de forma imediata; este é um processo mais complexo que envolve em alguns casos a luta pela verdade, o esclarecimento dos acontecimentos relacionados à perda, a justiça a participação em movimentos sociais, em processos psicoterapêuticos etc. Tal processo está condicionado por ações institucionais, sociais, familiares e redes de apoio. Não é apenas um percurso individual.

\section{Considerações finais}

A partir do que apresentamos neste artigo, podemos concluir que o vazio de sentido reaparece como sintoma: na falta de palavras, o corpo fala, o corpo se queixa, o corpo expressa o acontecimento traumático na forma de dores, doenças, aflições, agravos. A tragédia do desaparecimento do ente querido torna-se a causa dos mais variados agravamentos de saúde. Em outras palavras, as doenças tomam um sentido, elas se explicam em função da experiência violenta. Aquilo que não se resolve pela via simbólica, retorna no corpo. Por outro lado, o adoecimento é também uma tentativa de explicar a experiência violenta e uma manifestação 
da lembrança carregada de angústia do ente querido que sobrevive no psiquismo. Nesta lógica, as manifestações corporais e processos de adoecimento expressam a ambivalência dos familiares entre a vontade de esquecer e superar a perda, e a manutenção do sofrimento decorrente da incerteza da morte. Observamos sujeitos ancorados ao sofrimento que temem libertar-se dele porque presumem, através da fantasia, que os seus entes queridos permanecem vivos. Ao mesmo tempo, o adoecimento se apresenta como um vínculo identificatório entre familiares e os desaparecidos.

Como consequência do anterior entendemos que existe uma relação inseparável entre as dimensões psíquica e biológica da saúde, por um lado; e os aspectos subjetivos e sociais-culturais que a condicionam e determinam, por outro, tornando-a um fenômeno complexo e multifacetado. Neste caso, o acontecimento traumático se objetiva nos agravos de saúde que são significados como consequência direta da perda do ente querido.

Apesar das barreiras para a construção de sentido sob condições de incerteza, os familiares de desaparecidos realizam tentativas para significar a experiência violenta e elaborar o luto. O relato apresentado não condena às vítimas da violência a um enlutamento permanente. Pelo contrário, é possível reconhecer tentativas bem-sucedidas de superação da experiência traumática a partir de ações nos níveis individual, como a psicoterapia e os grupos de apoio; social, como a formação de associações de defesa das vítimas de violência; e institucional, entre as quais se destacam os processos de justiça e paz que procuram recuperar os depoimentos dos perpetradores dos crimes, realizar rituais coletivos de despedidas dos entes queridos e o julgamento dos responsáveis pelas desaparições. Essas três dimensões - individual, social e institucional - abrem a possibilidade para a superação da experiência violenta que pode ser observada enfim em uma lembrança sossegada da perda.

Por fim, argumentamos sobre a importância de futuras investigações orientadas a compreensão da experiência das vítimas de violência em diferentes contextos. Nesse sentido, é importante ressaltar que a perspectiva aqui adotada não se apoia em determinismos biológicos, sociais ou psicológicos. Da mesma forma, não nos alinhamos a um pensamento indeterminista radical, que colocaria a responsabilidade exclusiva da elaboração da experiência traumática na decisão do sujeito que a sofre, esquecendo aspectos históricos e culturais envolvidos. Acreditamos em uma perspectiva configuracional que integra elementos individuais, sociais e institucionais, mas sem negar a possibilidade de criação do inédito por parte do sujeito diante de situações extremas, como ficou evidente nas histórias dos entrevistados.

\section{Referências}

Butler, J. (2001). Mecanismos psíquicos del poder Madrid: Ediciones Cátedra.

Duque, C., Arango, L., \& Marín, U. (2010). Informe final de investigación: Reconfiguración de la identidad de familiares de personas que han sido víctimas de desaparición forzada en el marco del conflicto armado colombiano. Medellín: Centro de Investigaciones de la Fundación Universitaria Luis Amigó, convocatoria VIII del 2008.

Echavarria, J.D. L. (2011) Psicología y salud psíquica. Index de Enfermería, 20(1-2), 81-85. doi 10.4321/S1132-12962011000100017

Faciolince, V. D. (2008). Del dolor al duelo: límites al anhelo frente a la desaparición forzada. Affectio Societatis, (9),1-21. Recuperado de https://aprendeenlinea.udea.edu.co/revistas/index.php/ affectiosocietatis/article/view/5323/6578

Farias, F. R. (2008). Acontecimento traumático: fraturas da memória e descontinuidade histórica. In M. A. Barrenechea (Org.), As dobras da memória (pp. 101-112). Rio de Janeiro, RJ: 7 Letras.

Franco, S., Suares, C. M., Naranjo, C. B., Baez, L. C., \& Rozo, P. (2007) Efeitos do conflito armado sobre a vida e a saúde na Colômbia Ciência \& Saúde Coletiva, (11), 1247-1258. doi: 10.1590/ S1413-81232006000500014

Freud, S. (1996) Luto e melancolia. In S. Freud (Org.), A história do movimento psicanalítico: artigos sobre metapsicologia e outros trabalhos (1914-1916) - Edição Standard brasileira das Obras Psicológicas Completas de Sigmund Freud (Vol. XIV, pp. 249-263) Rio de Janeiro, RJ: Imago. (Obra original publicada em 1917)

Galeano, M. E. (2004). Estrategias de investigación social cualitativa: el giro de la mirada. Medellín: La Carreta.

Gennep, A.V. (2011). Os Ritos de passagem. (2ª ed.). Petrópolis, RJ Vozes.

González Rey, F. (2000). Investigación cualitativa en psicología: rumbos y desafíos. Ciudad de México, México: Paraninfo.

González Rey, F. (2005). Pesquisa qualitativa e subjetividade: os processos de construção da informação. São Paulo, SP: Pionera Thomson Learning.

Hernández-Holguín, D. M., \& Alzate-Gutiérrez, E. M. (2016). Experiencias de jóvenes de Medellín antes, durante y después de pertenecer a un grupo armado ilegal, 2005. Ciência \& Saúde Coletiva, 21(8), 2403-2412. doi: 10.1590/1413-81232015218.19742015

Honneth, A. (2003). Luta por reconhecimento. A gramática moral dos conflitos sociais. São Paulo: Editora 34.

Marín, M. E. G. (2004) Estrategias de investigación social cualitativa: el giro de la mirada. Medellín, Colombia: La Carreta.

Martín-Baró, I. (1990). Acción e ideología psicología social desde Centroamérica. (4aㅡ edição). San Salvador, El Salvador: UCA Editores.

Muñiz, O. A, Londoño, N. H., Correa, J. H., Patiño, C. D., \& Ochoa, D. A. R. (2005). Subjetivación de la experiencia violenta en el 
Sentidos de saúde e adoecimento na experiência de familiares de desaparecidos forçados

transtorno por estrés postraumático. Psicologia em Revista, 11(18), 188-204. Recuperado de: http://pepsic.bvsalud.org/pdf/per/v11n18/ v11n18a04.pdf

Patino, R. A., Chaves, A. M., \& Farias, F. R. (2015). Estado e grupos armados na Colômbia: carrascos, salvadores e experiência traumática. Psicologia \& Sociedade, 27(3), 629-639. doi: 10.1590/1807-03102015v27n3p629

Ricouer, P. (2010). A memória, a história e o esquecimento. Campinas, SP.: UNICAMP.
Rodriguez, J., De La Torre, A., \& Miranda, C. T. (2002). La salud mental en situaciones de conflicto armado. Biomédica, (22), 337-46 recuperado de https://www.revistabiomedica.org/index.php/biomedica/article/ viewFile/1183/1298

Stake, R. E (2007). Investigación con estudio de casos. ( $2^{\mathrm{a}}$ ed.). Madrid, España: Morata.

Unidad para la Atención e la Reparación Integral a las Víctimas (2017). Regístro Único de Víctimas. Recuperado de http://www. unidadvictimas.gov.co/

1. Para o aprofundamento das noções de trauma e trauma social, em contextos de violência, a partir de diferentes perspectivas teóricas, consultar: Patino, R. A., Châves, A. M., \& Farias, F. R. (2015). Estado e grupos armados na Colômbia: carrascos, salvadores e experiência traumática. Psicologia \& Sociedade, 27(3), 629-639.

2.Expressão que indica pensamento ou ideia fixa e recorrente.

Rafael Andrés Patiño, Doutor em Psicologia pela Universidade Federal da Bahia (UFBA), Pós-doutorado em Memória Social na

Universidade Federal do Estado do Rio de Janeiro (UNIRIO), é Professor Adjunto na Universidade Federal do Sul da Bahia (UFSB). Endereço para correspondência: Rua 15 de novembro, 300 Ap. 17 Centro Porto Seguro, BA - CEP 45.810-000.

Telefone: (73) 99967-5708. E-mail: rafaelpatino@ufsb.edu.br

Gabriela Lamego, Doutora em Saúde Pública pelo Instituto de Saúde Coletiva da Universidade Federal da Bahia (ISC/UFBA), é Professora Adjunta na Universidade Federal do Sul da Bahia (UFSB), E-mail: gabriela.lamego@gmail.com 